\title{
Geração de energia fotovoltaica - Pesquisa e desenvolvimento de geração isolada e conexão com o sistema de distribuição ${ }^{44}$ Photovoltaic power generation - Research and development on isolated generation and connection to the power grid
}

\author{
Rogers Demonti ${ }^{45}$ \\ Julio Shigeaki Omori \\ Michel Brantes \\ Cicero Laerte Gomes de Figueiredo
}

Artigo recebido em para publicação em ago/2012 e aceito para publicação em dez/2012.

\section{Resumo}

Este trabalho apresenta as características, o desenvolvimento e os resultados obtidos no projeto de P\&D (Pesquisa e Desenvolvimento) realizado entre o Instituto de Tecnologia para o Desenvolvimento - Lactec, e a Companhia Paranaense de Energia - Copel. O projeto intitulado Geração de energia fotovoltaica - Pesquisa e desenvolvimento de geração isolada e conexão com o sistema de distribuição, se propôs a estudar os

\footnotetext{
${ }^{44}$ Os autores agradecem a Agencia Nacional de Energia Elétrica - Aneel e a Copel, pelo apoio ao projeto, no âmbito do Programa de Pesquisa e Desenvolvimento - P\&D Aneel.
}

${ }^{45}$ Rogers Demonti é Doutor em Engenharia Elétrica pela Universidade Federal de Santa Catarina; pesquisador do Instituto de Tecnologia para o Desenvolvimento - Lactec; professor adjunto do Curso de Engenharia Elétrica da Universidade Federal do Paraná; email:

rogers@lactec.org.br

Julio Shigeaki Omori é Engenheiro Eletricista (UTFPR), Especialista em Automação de Processos Industriais (UTFPR), Mestre em Engenharia Elétrica e Informática Industrial (UTFPR), Engenheiro Eletricista Sênior e Gerente de Departamento de Manutenção de Subestações, Linhas de Transmissão e Automação da Copel Distribuição; email: julio.omori@copel.com

Michel Brantes é Engenheiro Eletricista - Pontifícia Universidade Católica do Paraná (PUCPR); Pós-graduando em Especialização em Eficiência Energética - Universidade Tecnológica Federal do Paraná (UTFPR); Pesquisador da divisão de eletrônica do Instituto de Tecnologia para o Desenvolvimento (LACTEC); email: michel.brantes@lactec.org.br

Cicero Laerte Gomes de Figueiredo é estudante de graduação em Engenharia Elétrica, $4^{\circ}$ ano, pela Universidade Positivo; Estudante de Iniciação Tecnológica - IT no Instituto de Tecnologia para o Desenvolvimento - Lactec; email: cicero.figueiredo@lactec.org.br 
impactos da conexão de sistemas de geração fotovoltaica como fonte de energia nos sistemas de distribuição através da implantação de um sistema completo interligado à rede de baixa tensão. O sistema opera em duas etapas distintas e simultâneas; uma conectada diretamente à rede e outra isolada, alimentado uma carga determinada. O sistema foi instalado em uma subestação de energia (SE) da Copel localizada em Fazenda Iguaçu, no município de Fazenda Rio Grande, na Região Metropolitana de Curitiba. A potência instalada total é de $8,1 \mathrm{~kW}$.

Palavras-chave: Módulos fotovoltaicos. Conexão à rede comercial. Sistemas isolados.

\section{Abstract}

This paper presents the characteristics, development and results obtained in the $R \& D$ project performed between Institute of Technology for Development (Lactec) and Companhia Paranaense de Energia (Copel). The project Photovoltaic power generation - Research and development on isolated generation and connection to the power grid, intended to study the role of photovoltaic energy sources connected at the distribution systems, through the deployment of a complete system interconnected to the low-voltage grid. The system operates in two distinct stages and simultaneous, the first connected directly to the grid and another stand-alone, feeding a specific isolated load. The system was installed in a Copel power substation located in the municipality of Fazenda Rio Grande, in the Curitiba Metropolitan Area. The total installed power is $8.1 \mathrm{~kW}$.

Keywords: Photovoltaic panels. Grid-tie. Stand-alone.

\section{Introdução}

A utilização da energia solar fotovoltaica tem muitos atrativos tais como a conversão direta de luz em eletricidade, a ausência de partes móveis, que reduz necessidades de manutenção, a operação silenciosa e segura, grande modularidade e rapidez na instalação além da fonte primária de energia, o Sol, ser praticamente inesgotável (FARRET. e SIMÕES, 2006). Entretanto alguns desafios ainda devem ser superados, tais como o custo dos módulos fotovoltaicos ${ }^{46}$ e a confiabilidade dos equipamentos eletroeletrônicos associados.

O projeto se encontra atualmente em operação produzindo energia elétrica no qual parte é enviada diretamente à rede durante o dia e outra parte é armazenada em um banco de baterias para alimentação e uma

\footnotetext{
${ }^{46}$ O termo módulo fotovoltaico é aqui utilizado para descrever a placa fotovoltaica, composta por 36 células de silício encapsuladas em uma estrutura de polivinil, alumínio e vidro temperado. O termo painel se refere à associação, em série e/ou paralelo, de vários módulos fotovoltaicos.
} 
carga à noite. Os dispositivos de monitorização, descritos na secção Materiais e Métodos, permitem o acompanhamento do sistema fotovoltaico à distância. As duas etapas, interligada e isolada, foram uma escolha inicial do projeto, com objetivo de se avaliar o comportamento dos módulos, inversores, e a própria disposição física da estrutura sob duas situações distintas, mas que configuram a maioria absoluta das aplicações para os módulos fotovoltaicos.

Atenção especial é dispensada aos inversores utilizados no projeto já que a geração elétrica dos módulos fotovoltaicos ocorre em corrente contínua e a rede comercial, bem como a maioria dos equipamentos elétricos, operam em corrente alternada. Portanto a conversão de energia deve ser realizada com a máxima eficiência através destes inversores (DEMONTI e MARTINS, 2002) para que o tempo de retorno financeiro seja o menor possível.

\section{Escolha dos módulos fotovoltaicos}

Foram realizadas pesquisas sobre as tecnologias utilizadas atualmente em relação aos módulos fotovoltaicos. A maioria absoluta produzida no mundo usa o silício como principal material na fabricação das células fotovoltaicas.

Existem no mercado 4 tecnologias mais utilizadas para células fotovoltaicas; silício monocristalino, silício policristalino, silício amorfo e filmes finos.

\section{Células de silício monocristalino}

As células monocristalinas de silício representam a primeira geração. O seu rendimento de conversão é relativamente elevado podendo chegar até $29 \%$ em laboratório (GREEN, 1982), mas as técnicas utilizadas na sua produção são complexas e caras. Por outro lado, é necessária uma grande quantidade de energia na sua fabricação devido à exigência de silício muito puro e com uma estrutura cristalina perfeita. As células são obtidas a partir de barras cilíndricas de silício monocristalino produzidas em fornos especiais. São cortadas barras em forma de pastilhas finas $\left(0,4-0,5 \mathrm{~mm}^{2}\right)$. A sua eficiência na conversão da luz solas em eletricidade, quando nos módulos, é superior a $18 \%$.

\section{Células de silício policristalino}

Estas células são produzidas a partir de blocos de silício obtidos por fusão de silício puro em moldes especiais. Uma vez nos moldes, o silício esfria lentamente e solidifica-se. Neste processo, os átomos não se organizam num único cristal. Forma-se uma estrutura policristalina com superfícies de separação entre os cristais. Sua eficiência na conversão de luz solar em eletricidade é ligeiramente menor do que nas de silício monocristalino. 
As células policristalinas têm um custo de produção inferior por necessitarem de menos energia na sua purificação, mas apresentam um rendimento elétrico inferior (18\% em laboratório e 14\% em módulos). Esta redução de rendimento é causada pelas imperfeições da estrutura cristalina.

\section{Células de silício amorfo}

Estas células são feitas com materiais nos quais as estruturas cristalinas apresentam alto grau de desordem. Com custo reduzido, têm eficiência da conversão entre $8 \%$ a $10 \%$.

Com o silício amorfo pode-se construir as células de filmes finos por meio da deposição de camadas finas sobre superfícies de prata. A melhor aplicação para essa tecnologia está em calculadoras, relógios e outros produtos onde o consumo de energia é baixo. Tais células funcionam também sob iluminação artificial. O resultado são módulos flexíveis inquebráveis, mais leves, semitransparentes, com superfícies curvas, que ampliam o mercado fotovoltaico por sua maior versatilidade. Em algumas aplicações arquitetônicas como material de revestimento é que o silício amorfo tem grande vantagem sobre as células convencionais, pois o custo por metro quadrado, e não o custo por watt produzido, é a grandeza de interesse. Neste aspecto estas células tem um custo competitivo.

Outros materiais também são utilizados, entre eles, temos as tecnologias de CIGS (Cobre-Índio-Gálio-Selênio), GaAs (Arsenieto de Gálio) e células CdTe (Telureto de cádmio).

A tabela a seguir resume as informações sobre as tecnologias comerciais de maior utilização atualmente, assim como as potências e tensões de operação dos módulos.

\begin{tabular}{l|l|l|l} 
Tecnologia & $\begin{array}{l}\text { Potências } \\
\text { disponíveis [W] }\end{array}$ & $\begin{array}{l}\text { Tensões de } \\
\text { operação [V] }\end{array}$ & $\begin{array}{l}\text { Disponibilidade } \\
\text { commercial }\end{array}$ \\
\hline Filmes Finos Flexíveis & 1 a 32 & 16,5 & Media \\
\hline Policristalino & 50 a 205 & 17,5 & Alta \\
\hline Monocristalino & 20 a 150 & 17,5 & Baixa
\end{tabular}

Tabela 1: Resumo das três tecnologias de módulos fotovoltaicos mais disponíveis comercialmente.

Baseado em informações de comercializadoras de módulos fotovoltaicos é possível afirmar que a tecnologia mais adequada para implantação de módulos fotovoltaicos, tanto em sistemas isolados como interligados, é a que utiliza silício policristalino por seu avançado grau de utilização e fabricação, menor custo por potência gerada e disponibilidade comercial. Desta forma, este projeto utiliza módulos de tecnologia de silício policristalino. Em relação ao custo por potência gerada os módulos de filmes finos são bastante competitivos. Entretanto há relatos, ainda não confirmados tecnicamente, de perda de potência mais acentuada ao longo 
da vida útil do módulo. Observou-se assim, que a tecnologia de módulos fotovoltaicos que mais se adéqua aos propósitos deste projeto é a que utiliza silício policristalino. Esta definição também levou em consideração fatores econômicos já que o orçamento para o projeto estava adequado, porém não permitia testes com tecnologias mais caras.

De acordo com a Figura 1, o sistema fotovoltaico é composto por três painéis, com potência total de 8,1 kW. Foram escolhidos $5,4 \mathrm{~kW}$ para conectar à rede através de dois inversores e 2,7 kW para alimentar um banco de baterias.

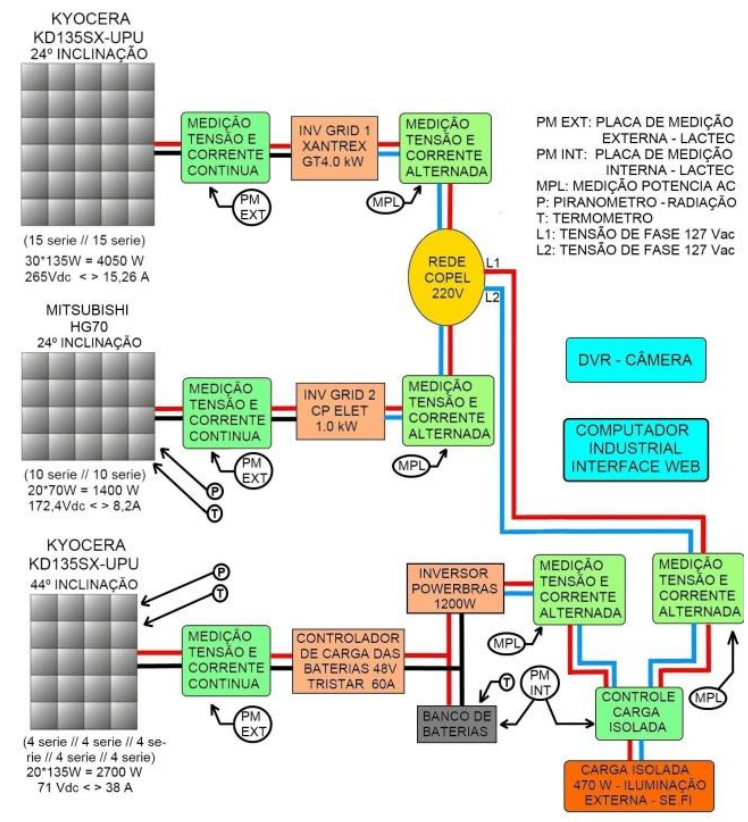

Figura 1: Diagrama resumido da configuração dos principais elementos do sistema fotovoltaico do projeto.

A autonomia projetada do banco de baterias é de um dia, considerando-se a menor média diária típica do ano, para a localidade de Fazenda Rio Grande.

\section{Materiais e Métodos}

Esta etapa descreve os principais componenetes utilizados no projeto e suas características, assimcomo a metologia utilizada na coleta e análise das informações.

Os principais componenetes do sistema são descritos a seguir. 


\section{Módulos fotovoltaicos}

No projeto são utilizados dois modelos de módulos fotovoltaicos:

HG70, da Mitsubishi, com potência de $70 \mathrm{~W}$, tensão de 17,2 V e corrente de $4,1 \mathrm{~A}$ no ponto de máxima potência (m.p.p.). Estes módulos foram fornecidos pela Copel.

Módulos KD135SX da Kyocera, com potência de 135 W, tensão de $17,7 \mathrm{~V}$ e corrente de 7,6 A no m.p.p.

\section{Inversores}

O primeiro é o inversor modelo CP1000, da empresa CP Eletrônica. Possui potência de $1,1 \mathrm{~kW}$, com tensão de saída de $220 \mathrm{~V}$. A faixa de tensão de entrada situa-se entre $160 \mathrm{~V}$ e $300 \mathrm{~V}$. Possui sistema de m.p.p.t. (seguidor de ponto de máxima potência), isolação galvânica entre os painéis e a rede elétrica através de transformador isolador e proteção anti-ilhamento.

O segundo modelo é o GT4.0-NA-240/208, da empresa Xantrex. Foi fornecido pela Copel e processa $4 \mathrm{~kW}$, com tensão de saída de $240 \mathrm{~V}$. A faixa de tensão de entrada situa-se entre 195 V a 550 V. Possui sistema de m.p.p.t.

O terceiro inversor, modelo ISP 48-1200B da Powerbras, alimenta a carga isolada tem tensão fixa na saída, ou seja, opera com fonte de tensão. Possui tensão de entrada de $48 \mathrm{~V}$ e tensão de saída: $220 \mathrm{~V}$ senoidal, com potência de $1200 \mathrm{~W}$. A escolha de um modelo senoidal previne problemas causados por harmônicas em cargas sensíveis.

A principal dificuldade encontrada nesta etapa foi o fato de não haver sistemas comerciais de elevada tensão para realizar o controle de carga das baterias. Por outro lado há dificuldades para adquirir no mercado inversores com tensões compatíveis com as do controlador de carga.

Outra questão a ser observada é o fator de dimensionamento do inversor (FDI), que é a relação entre a potência nominal do inversor e a potência do gerador fotovoltaico. Pode-se analisar a situação mais adequada considerando-se o critério da maior produção anual de energia e consequentemente a melhor eficiência do sistema (maior $\mathrm{kWh} / \mathrm{kWp}$ ); e o que fornece o menor custo da energia produzida (MACÊDO, 2004). Conforme a literatura, valores de FDI devem ser inferiores a 0,8, independentemente da região do país. Contudo, dos resultados obtidos, tanto por meio de simulações como por dados experimentais, verifica-se que há uma margem flexível quanto a sua utilização. 


\section{Controlador de carga}

Este dispositivo é responsável por interligar o painel 2, conforme Figura 1, às baterias e gerenciar a carga, obtendo máximo desempenho dos módulos É o modelo TriStar MPPT-60 da fabricante Morningstar. O principal objetivo do controlador é manter a bateria dentro de condições ideais de funcionamento, assegurando assim longa vida útil ao banco. A corrente e a tensão nominais de saída são $60 \mathrm{~A}$ e $48 \mathrm{~V}$, respectivamente. Este modelo foi escolhido pelas suas características de tensão de entrada e saída, capacidade de corrente e presença do m.p.p.t.

\section{Sensores de radiação}

Foram instalados os sensores de radiação que fornecem dados da incidência solar nas inclinações dos painéis. Desta forma pode-se conhecer a potência gerada pela irradiação solar no local do projeto. Trata-se do sensor CR100A da Kimo, que mede radiação solar na faixa dos 400 a $1100 \mathrm{~nm}$ até $1300 \mathrm{~W} / \mathrm{m}^{2}$. A Figura 2 apresenta o sensor que é fixado na mesma inclinação dos painéis.

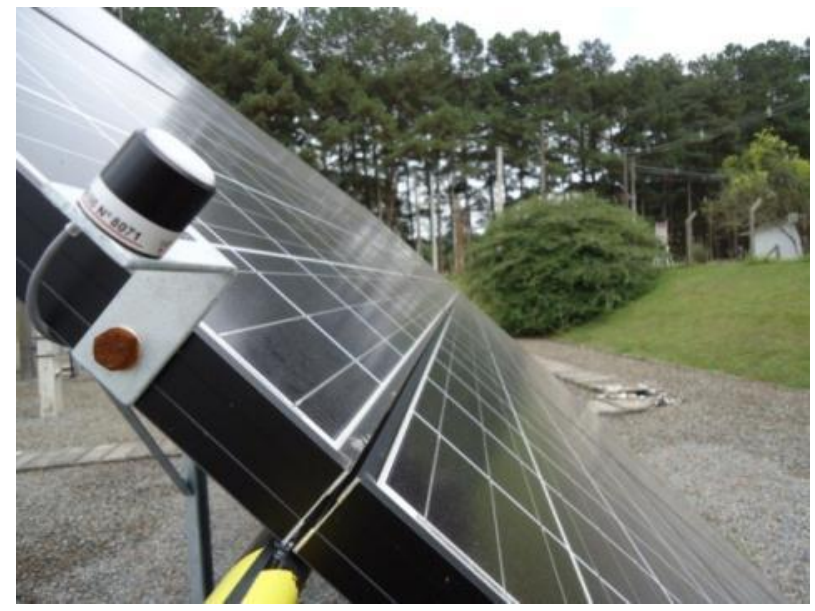

Figura 2: Sensor de radiação instalado nos painéis.

\section{Carga isolada}

O objetivo da carga isolada é realizar o consumo da energia armazenada no banco de baterias. É composta por duas luminárias com lâmpadas de vapor de sódio de $400 \mathrm{~W}$ e $70 \mathrm{~W}$ que iluminam parte da SE à noite. São acionadas por uma célula fotoelétrica de forma que o período de fornecimento de energia é de aproximadamente 12 horas. 


\section{Banco de baterias}

O banco de baterias (Figura 13) tem o objetivo de suprir de energia a etapa isolada do projeto, alimentando-a à noite. Considerando a disponibilidade financeira foi possível a atender o sistema isolado com uma autonomia de 1 dia de operação, para ciclos diários de descarga máxima de $20 \%$. Desta forma a vida útil do banco é priorizada.

Em uma parceria com a empresa Acumuladores Moura, um conjunto de 12 baterias foi doada para o projeto. São da linha Clean Nanotechnology, modelo 12MF220, com capacidade de 220 Ah cada.

$O$ banco foi associado em três grupos de 4 baterias em série e depois associados em paralelo, totalizando $48 \mathrm{~V}$ e 660 Ah. A seguir observa-se o aspecto final do banco de baterias.

\section{Circuito de controle e monitoramento de grandezas}

O circuito eletrônico para monitoramento, que foi desenvolvido pelos pesquisadores do Lactec, é composto por um computador, diversos sensores e dois circuitos específicos que ficarão, um (A) no interior da sala da SE e outro (B) junto dos painéis. A placa A contém os circuitos para medição da tensão de cada bateria do banco, medição da corrente total que entra e que sai do banco além do monitoramento da temperatura do banco. Os sinais analógicos são convertidos para valores digitais e em seguida enviados ao computador. Estas informações servem para tomada de decisão do controle e acompanhamento remoto.

A placa $B$, reúne dados dos sensores de radiação e de temperatura dos painéis. As informações também são digitalizadas e enviadas ao computador. específicos.

$\mathrm{Na}$ Figura 3 observa-se o diagrama de blocos dos circuitos

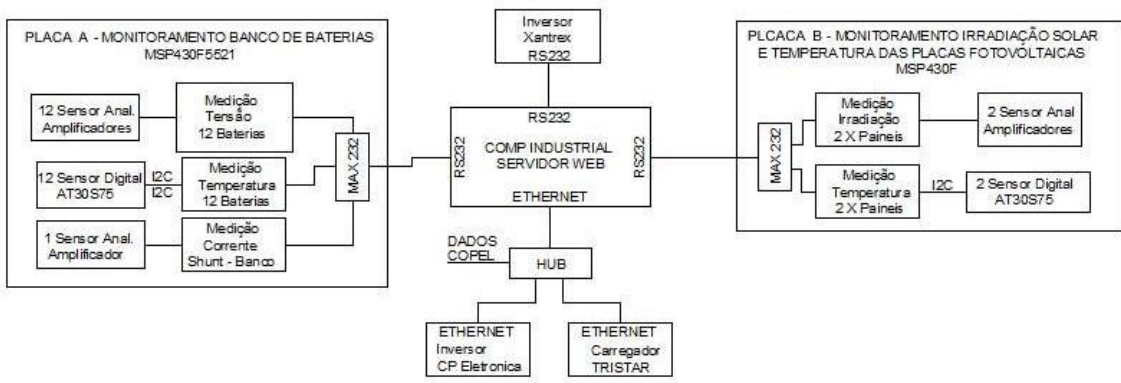

Figura 3: Diagrama de blocos das placas A e B.

O correto monitoramento do banco pode prevenir, por exemplo, uma descarga exagerada que provocaria uma diminuição da vida útil das 
baterias. Um pequeno computador industrial agrupa todas as informações e permite a geração de relatórios de vários períodos de tempo.

\section{Estrutura metálica}

A estrutura metálica fixa é responsável por suportar todos os módulos fotovoltaicos. Devido ao fato de se ter dois sistemas, um isolado e um interligado, as inclinações destes painéis deve ser distinta para se obter dois perfis anuais de produção de energia nos planos inclinados de $44^{\circ} \mathrm{e}$ $24^{\circ}$ respectivamente.

Os perfis das estruturas podem ser vistos na figura a seguir.

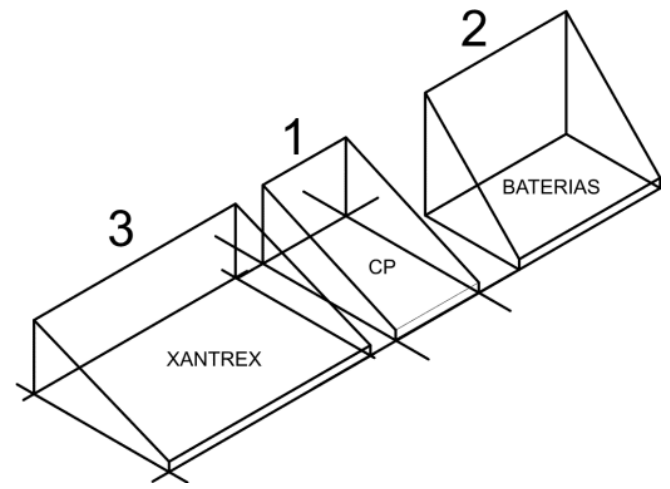

Figura 4: Disposição das estruturas metálicas dos três painéis do projeto.

As dimensões das estruturas fora projetadas de acordo com as inclinações e também com as dimensões dos módulos fotovoltaicos e suas respectivas conexões elétricas. Por sua vez, as conexões elétricas foram definidas em função das tensões de entrada dos inversores e do banco de baterias. Todas as partes metálicas foram galvanizados a fogo para que estas acompanhem a vida útil dos módulos fotovoltaicos, estimada em 25 anos.

\section{Cálculos e análises}

No processo de definição do local de instalação do sistema, vários fatores influenciaram na decisão. O município de Fazenda Rio Grande foi escolhido por ser uma das cidades que a Copel testa projetos de automação do sistema de distribuição de energia elétrica (JORNAL DO ESTADO, 2010).

Após visitas realizadas pelos pesquisadores do Lactec e da Copel à SE Fazenda Iguaçu, em Fazenda Rio Grande concluiu-se que o local atendia as necessidades para instalação do projeto, nos itens segurança, espaço físico, facilidade de conexão à rede elétrica, comunicação e acessibilidade. 
Para a aplicação interligada e para a isolada, foi necessário, ainda, realizar um estudo sobre a disponibilidade solarimétrica da região, de forma a se determinar a quantidade de energia disponível.

O Município de Fazenda Rio Grande (Figura 5), está localizado a uma latitude de $-25^{\circ} 39^{\prime} 28^{\prime \prime}$ e longitude de $49^{\circ} 18^{\prime} 28^{\prime \prime}$, com altitude de 910 metros.

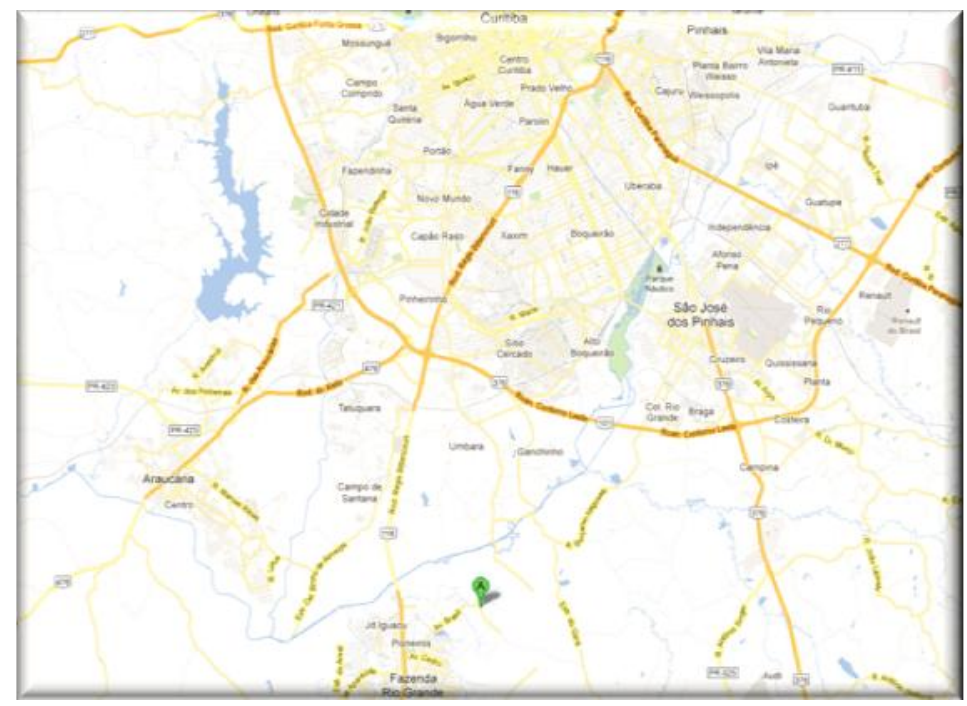

Figura 5: Localização da planta de geração fotovoltaica.

Através da observação de mapas de irradiação solar para o Brasil, tais como 0 apresentado na Figura 6, nota-se as diferenças de irradiações solares médias mensais para meses opostos (Janeiro e Julho). Fatores tais como a nebulosidade e o albedo, que é a relação entre a luz refletida pela superfície de um planeta e a luz que este recebe, também foram considerados (MARTINS et al., 2005). 

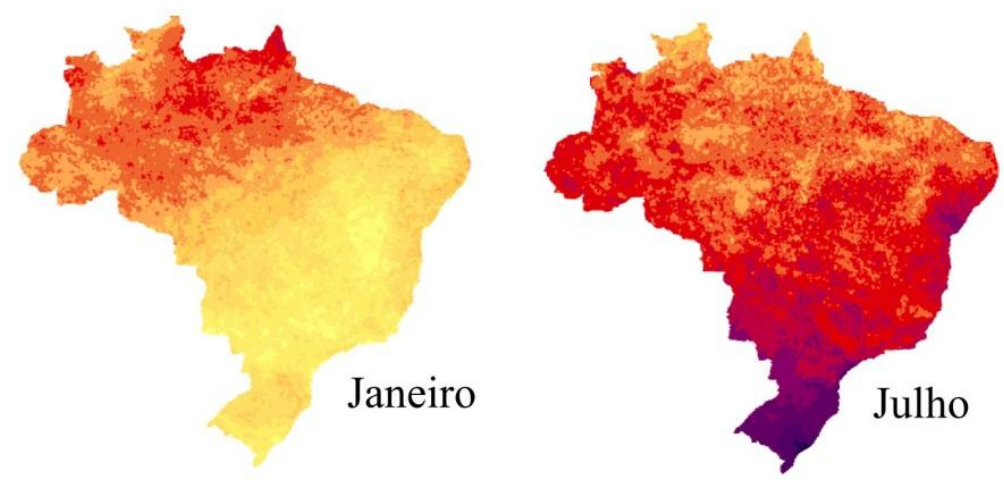

$\mathrm{kWh} / \mathrm{m}^{2} / \mathrm{dia}$

Figura 6: Mapa de irradiação solar no Brasil para dois diferentes meses do ano. Fonte: Martins et al. 2005.

Estes mapas permitem criar uma tabela de irradiações solares globais médias mensais para uma determinada região do globo terrestre. A Tabela 2 apresenta quatro linhas com valores de radiação diária média mensal para a região de Fazenda Iguaçu, distante $25,8 \mathrm{~km}$ do ponto central da cidade de Curitiba (CRESESB, 2011). A primeira linha, por exemplo, apresenta a radiação no plano horizontal ao longo dos meses do ano. Observa-se a maior média anual é obtida a $21^{\circ}$ de inclinação e o maior mínimo mensal à 45ㅇ. Estes fatores são importantes para o sistema conectado à rede e para o isolado, respectivamente, causando impacto diretamente no custo de implantação e de retorno de investimento.

Cálculo no Plano Inclinado

Municipio: Curitiba - PR

Latitude: $25,427777^{\circ} \mathrm{Su}$

Longitude: $49,273055^{\circ}$ Oeste

Distância: $25,8 \mathrm{~km}$

\begin{tabular}{|c|c|c|c|c|c|c|c|c|c|c|c|c|c|c|c|c|}
\hline & \multicolumn{14}{|c|}{ Radiação diária média mensal [kwh/m².dia] } \\
\hline \# & Ângulo & Inclinação & Jan & Fev & Mar & Abr & Mai & Jun & Jul & Ago & Set & Out & Nov & Dez & Média & Delta \\
\hline V & Plano Horizontal & $0^{\circ} \mathrm{N}$ & 4,67 & 4,11 & 3,47 & 3,06 & 2,53 & 2,47 & 3,11 & 3,31 & 3,67 & 4,22 & 4,94 & 5,06 & 3,72 & 2,59 \\
\hline v & Ângulo igual a latitude & $26^{\circ} \mathrm{N}$ & 4,23 & 3,92 & 3,54 & 3,42 & 3,08 & 3,21 & 4,08 & 3,92 & 3,91 & 4,12 & 4,52 & 4,50 & 3,87 & 1,43 \\
\hline च & Maior média anual & $21^{\circ} \mathrm{N}$ & 4,35 & 4,00 & 3,56 & 3,39 & 3,01 & 3,10 & 3,94 & 3,85 & 3,90 & 4,18 & 4,64 & 4,65 & 3,88 & 1,64 \\
\hline ( & Maior minimo mensal & $45^{\circ} \mathrm{N}$ & 3,60 & 3,47 & 3,29 & 3,39 & 3,21 & 3,44 & 4,39 & 4,00 & 3,73 & 3,70 & 3,86 & 3,77 & 3,65 & 1,19 \\
\hline
\end{tabular}

Tabela 2: Radiação média no plano inclinado.

\section{Estimativa da energia gerada no ano}

Uma parte dos módulos fotovoltaicos foram adquiridos novos $(6,7 \mathrm{~kW}) \mathrm{e}$ outra parte $(1,4 \mathrm{~kW})$ foi aproveitada de um pequeno conjunto de módulos 
fotovoltaicos e inversor provenientes de projetos anteriores de eletrificação da Copel.

Como o projeto em questão envolve dois sistemas distintos; um interligado à rede comercial e outro isolado, é importante que se utilize, para o interligado, a inclinação que maximize a energia anual (valor médio de $3,88 \mathrm{kWh} / \mathrm{m}^{2} /$ dia) e, para o isolado, se maximize a energia gerada no pior mês do ano (valores destacados em vermelho $\left(3,21 \mathrm{kWh} / \mathrm{m}^{2} /\right.$ dia) na Tabela 2).

Assim os painéis 1 e 3 da Figura 4 foram posicionados em uma inclinação de $24^{\circ}$, e o painel 2 , que alimenta o banco de baterias, em $44^{\circ}$, considerando questões construtivas. É importante notar que a inclinação de 44ํ não fornece maior energia anual mas permite gerar a máxima energia nos meses de baixa insolação. Assim o projeto do banco de baterias também é otimizado, visando máxima autonomia.

Considerando-se o painel 1 com potência instalada de $5,4 \mathrm{~kW}$ e o painel 2 com 2,7 kW, obtém-se a Tabela 3.

\begin{tabular}{c|c|c} 
Potëncıa do paınel $[\mathrm{kW}\rfloor$ & Disponıbılıdade solarımetrıca $[\mathrm{kWh} /(\mathrm{m} 2 . \mathrm{d} ı \mathrm{a})] 4 /$ & I otal [kWh/dia] \\
\hline 1,4 & $3,8 /$ & 5,4 \\
\hline 4,0 & $3,8 /$ & 15,5 \\
\hline 2,1 & 3,65 & 9,9 \\
\hline 8,1 & Total dos 3 painéis & 30,8
\end{tabular}

Tabela 3: Estimativa da energia produzida por diversos módulos fotovoltaicos submetidos a uma curva de irradiação anual da Tabela 2.

A partir do cálculo da energia produzida foram definidas as etapas seguintes do projeto, tais como a disposição e quantidade dos módulos fotovoltaicos sobre a estrutura metálica, assim como o projeto da estrutura física.

\section{Resultados}

Todos os equipamentos foram testados em laboratório antes de serem instalados. Para validar o algoritmo de rastreamento do ponto de máxima potência (MPPT) dos inversores, foram utilizadas fontes de alimentação com ajustes dos limites de correntes CC de modo a produzir as tensões necessárias aos inversores. Esta é uma forma de se testar, com fontes comuns, inversores para módulos fotovoltaicos, já que o algoritmo de MPPT presente nesses inversores causa um efeito de curto-circuito nas fontes de tensão sem limitação de corrente. As fontes de tensão foram limitadas em 1 ampère, proporcionando o funcionamento do sistema MPPT quando o inversor ajusta o nível de potência drenada com a potência disponível nas fontes. Nesta oportunidade foram realizados testes para

${ }^{47}$ Irradiação diária média mensal. 
verificar, na etapa conectada à rede, o efeito da falta de energia. O objetivo foi de medir quanto tempo demora o inversor para se desligar na falta da rede, com o sol presente nos módulos. Esta é uma característica importante nos inversores conectados diretamente à rede para garantir segurança e evitar o efeito de ilhamento.

As imagens foram adquiridas com um osciloscópio digital e os resultados são mostrados a seguir para a tensão da rede comercial e a corrente na saída do inversor. A Figura 7 mostra a tensão em corrente em regime permanente e a Figura 8 mostra o que ocorre com a tensão e a corrente na saída do inversor quando o disjuntor que conecta-o à rede é desligado. A corrente (em verde) instantaneamente vai a zero e a tensão nos terminais do inversor permanece por aproximadamente meio ciclo em valor intermediário e finalmente vai a zero também.

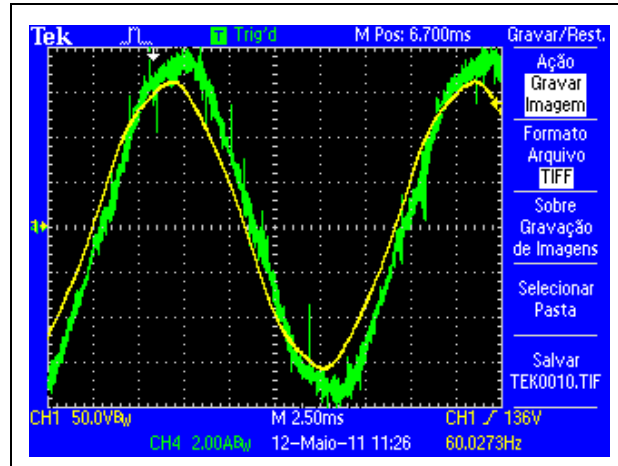

Figura 7: Tesão (amarelo) e corrente (verde) na saída do inversor.

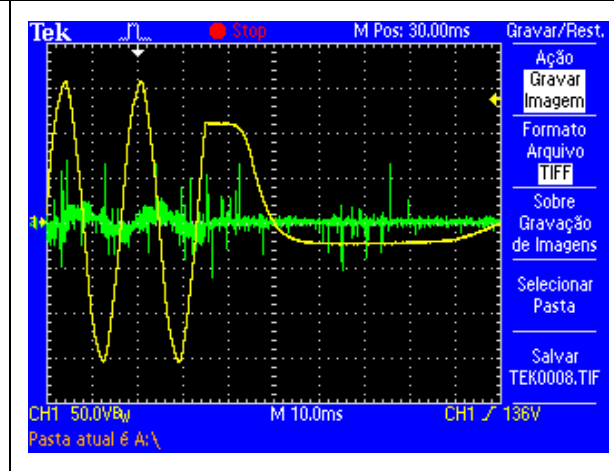

Figura 8: Desligamento do disjuntor de conexão inversor-rede comercial.

Foi escolhido um dia com sol, porém apresentava uma nebulosidade fraca. O local da instalação para o teste foi a cobertura prédio sede do Lactec. A Figura 9a mostra a conexão dos módulos e a Figura 9b o painel completo sendo iluminado pelo sol. Como o objetivo era apenas testar o inversor com os módulos, não houve preocupação em garantir inclinação ótima já que a finalidade era comprovar a operação.

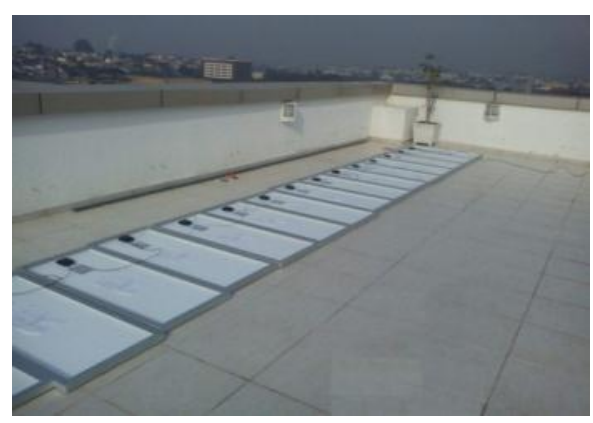

Figura 9: a) Módulos cobertos e conexões elétricas na parte inferior.

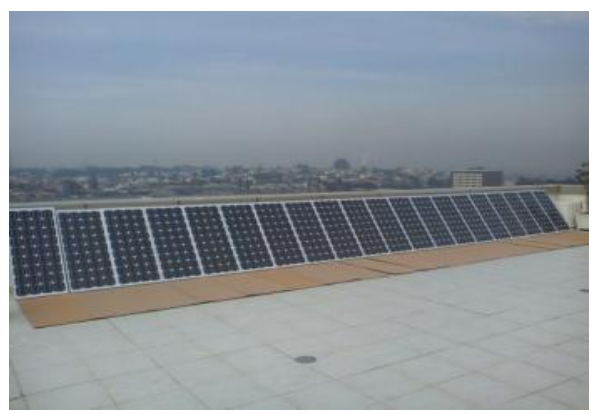

b) Disposição do painel iluminado. 
Também foi testada etapa isolada do projeto fotovoltaico com as baterias e cargas. A Figura 10 apresenta um aspecto destes testes. Nesta oportunidade pôde-se observar o desempenho do inversor senoidal ISP 481200B e do controlador de carga TriStar MPPT-60.
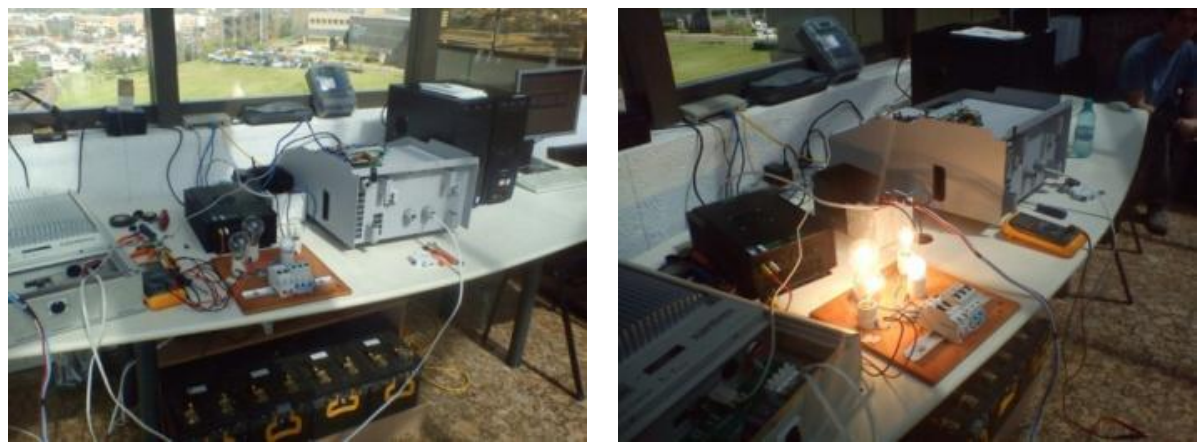

Figura 10: Teste da etapa de armazenamento do projeto.

A Figura 11 mostra como ocorre a entrada do inversor na rede, em um intervalo de 50 s quando o disjuntor é religado.

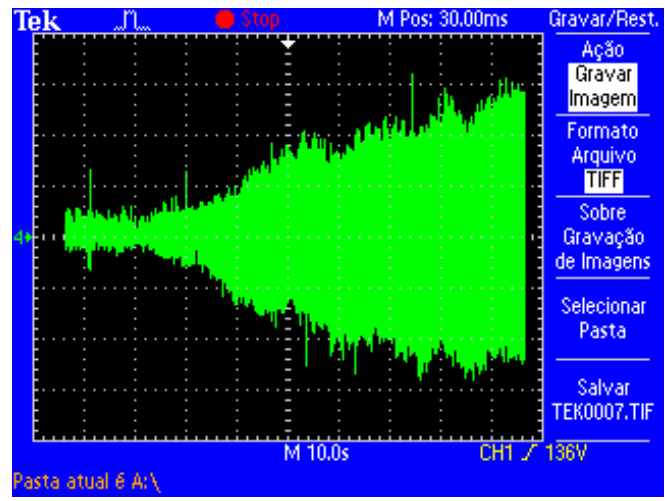

Figura 11: Processo de entrada em operação do inversor. Nesta situação o painel já está iluminado.

A entrada em operação ocorre lentamente neste intervalo.

\section{Instalação em campo}

$\mathrm{Na}$ SE Fazenda Iguaçu, foi demarcado do local onde ficariam os painéis. Nesta ocasião foi determinada a direção norte geográfica e fixadas marcas para as bases de concreto e a estrutura metálica. 


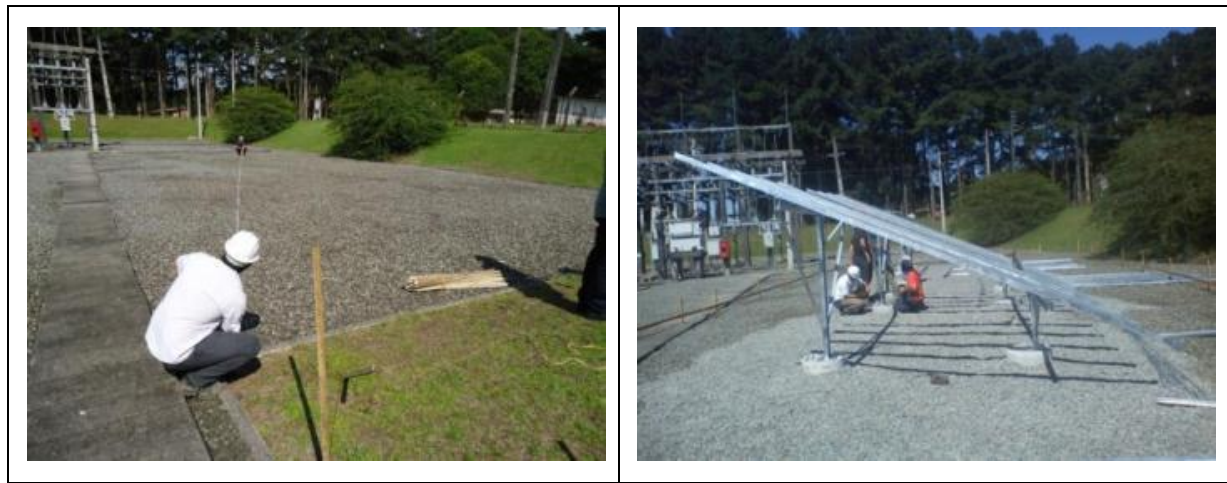

Figura 12: Etapas intermediárias na implantação dos painéis.

O sistema fotovoltaico foi colocado em operação no dia 20 de Abril de 2012. Inicialmente os inversores interligados à rede foram energizados. Para medição independente daquelas que os inversores fornecem, há medidores comerciais que monitorarão as energias de entrada e saída dos diversos pontos do sistema.

A Figura 13 apresenta o aspecto da disposição interna dos equipamentos no local da planta fotovoltaica.

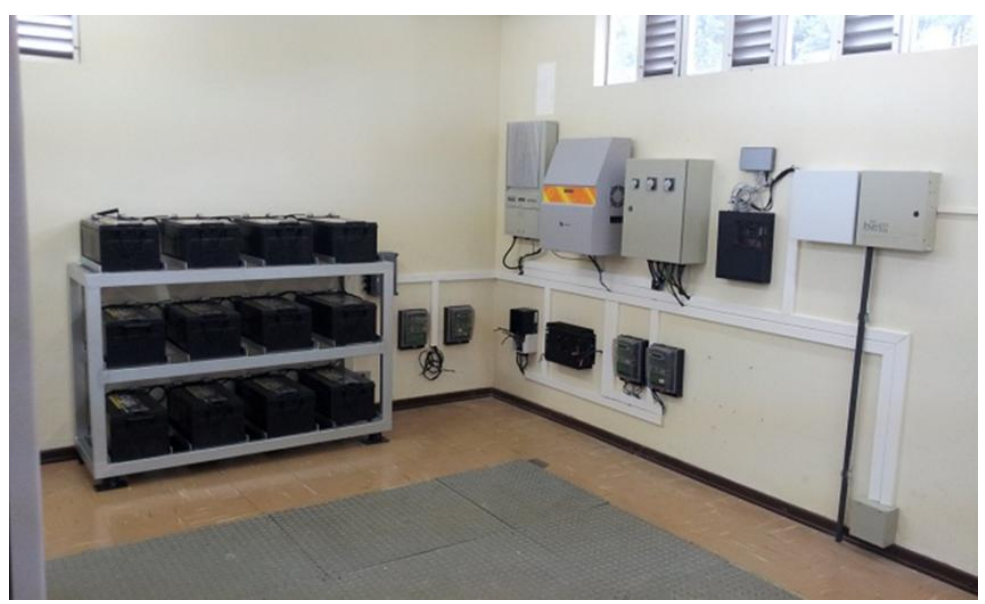

Figura 13: Disposição dos inversores, medidores de energia, quadro de comando e banco de baterias do sistema fotovoltaico na subestação Fazenda Iguaçu.

A Figura 14 apresenta o aspecto final dos painéis. 


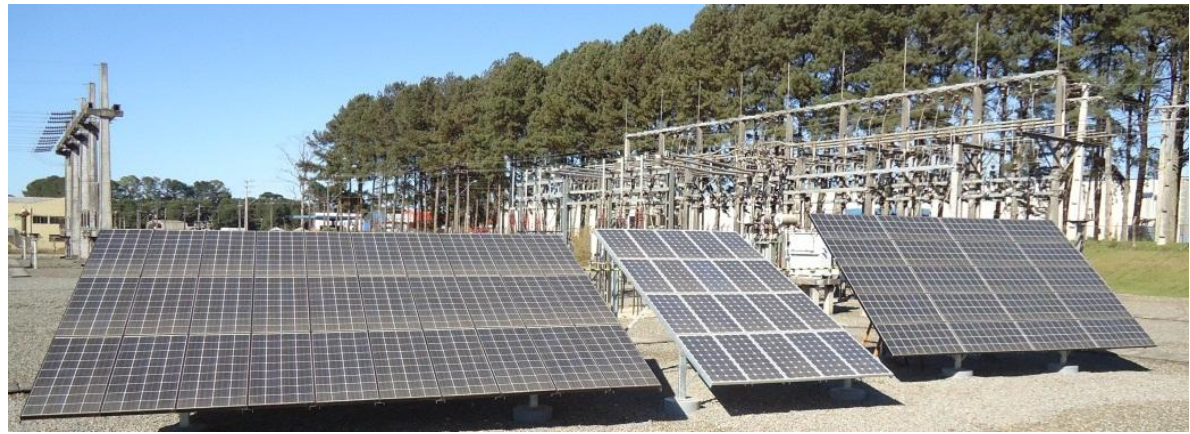

Figura 14: Painéis fotovoltaicos da planta solar.

Com o circuito de controle e monitoramento de grandezas em operação pôde-se reunir dados de geração de energia. No período de 21/10/2012 a 21/11/2012 foram coletados dados de irradiância através dos sensores de radiação além da energia gerada diariamente com os inversores Xantrex e CP. A Figura 15 apresenta valores de irradiação, em $\mathrm{W} / \mathrm{m}^{2}$, para o dia $18 / 10 / 2012$ nos planos inclinados de $24^{\circ}$ e $44^{\circ}$.

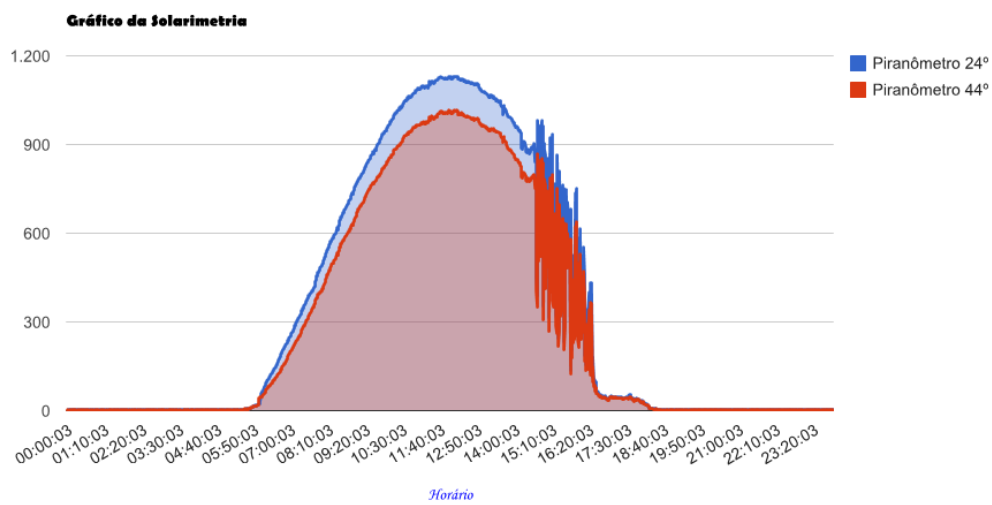

Figura 15: Curvas de irradiância nos planos inclinados de $24^{\circ}$ e 44ำ na localização da planta fotovoltaica, para o dia 18/10/2012.

Estas medições mostram um dia ensolarado com incidência de nuvens a partir das 15:00 $\mathrm{h}$.

Realizando-se a integração desta potência ao longo do dia, obtémse a energia disponível, que pode ser observada na Figura 16. 

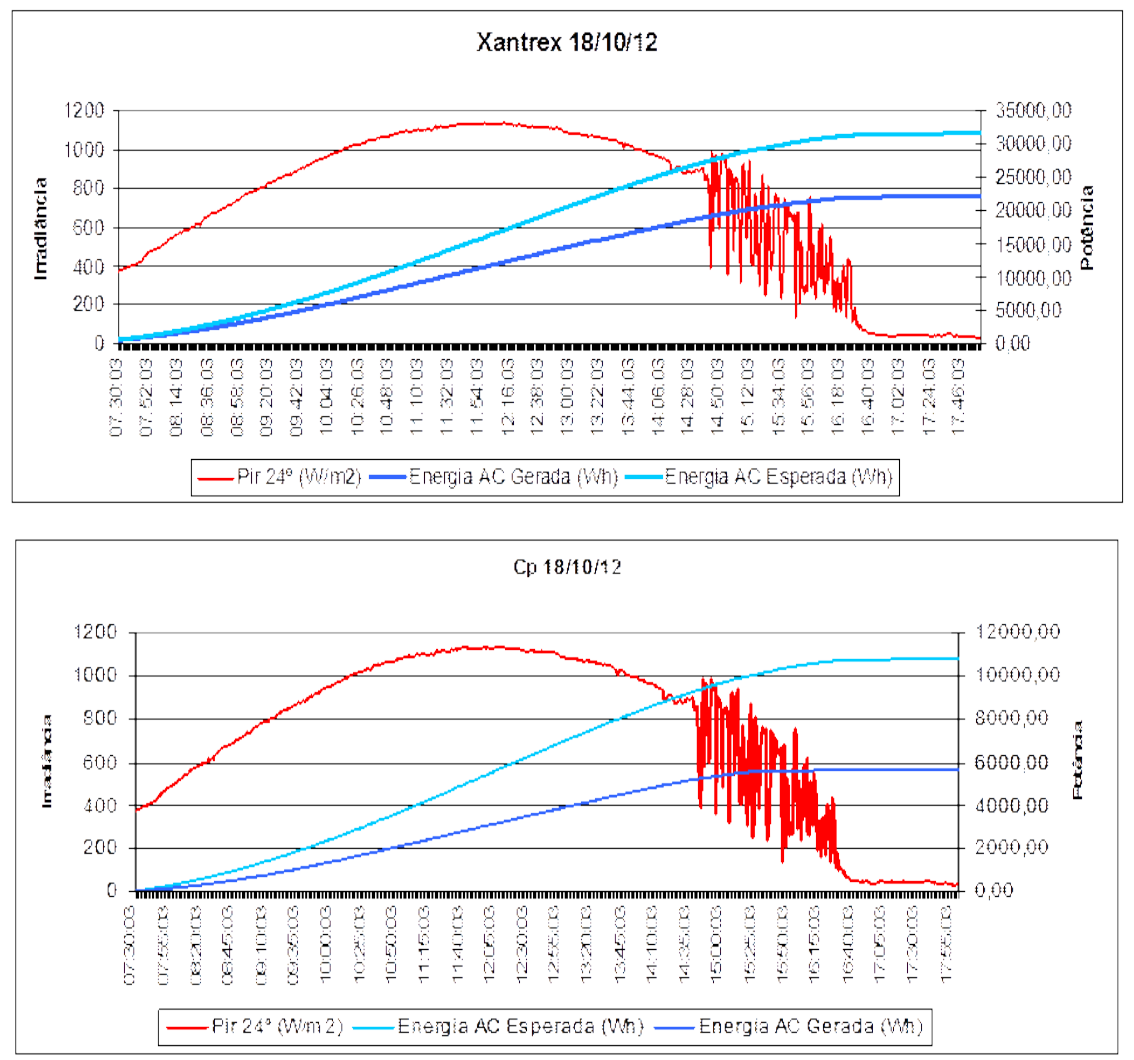

Figura 16: Curvas experimentais de irradiância medida, energia calculada e medida para cada um dos inversores conectados à rede comercial.

Há uma diferença clara entre as curvas de energia esperada e energia gerada de fato pelos inversores. Deve-se contabilizar todas as perdas de energia do sistema, que incluem a transmissão da energia dos painéis à sala dos inversores, perdas de conversão e, principalmente, efeitos da temperatura no rendimento dos módulos fotovoltaicos para compreender a diferença. Outro fator importante para a diferença está no FDI (secção Materiais e Métodos). O inversor CP, de 1,1 kW está conectado a um painel de 1,4 kW. Naturalmente há uma limitação de potência pelo inversor.

O gráfico da Figura 17 apresenta a energia disponível no plano inclinado de $24^{\circ}$, medida pelo sensor de radiação e produção média dos dois inversores conectados à rede.

$\mathrm{Na}$ tabela faltam alguns dados, nos dias em que o sistema foi desligado para medições internas, instalação de dispositivos, ajustes e calibrações dos sensores e medidores de energia. 


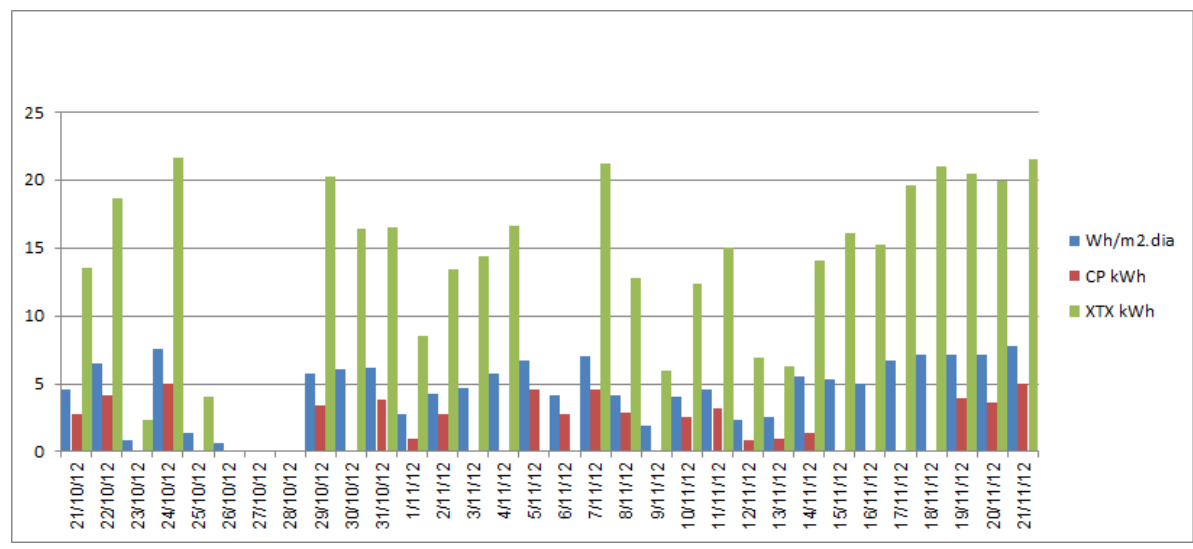

Figura 17: Energia incidente (Wh/m2.dia) e produzida pelos inversores CP e Xantrex para o meses de Outubro/Novembro de 2012.

A produção média neste intervalo foi de 15,2 kWh/dia com uma disponibilidade média medida de $4,88 \mathrm{kWh} / \mathrm{m}^{2} /$ dia. Observando a Tabela 2 nos meses de Outubro e Novembro, nota-se que a média fica em 4,32 $\mathrm{kWh} / \mathrm{m}^{2} /$ dia para inclinação de $26^{\circ}$, que representou uma radiação $13 \%$ maior para o ano de 2012 neste intervalo.

A produção de energia, considerando-se uma potência instalada e conectada à rede de $5400 \mathrm{~W}$, seria de 20,5 kWh/dia @ 4,32 kWh $/ \mathrm{m}^{2} /$ dia. Com as paradas para manutenção o valor produzido ficou $26 \%$ menor. Uma perda estimada de $12 \%$ foi atribuída ao processamento de energia e demais perdas nas conexões e cabos elétricos. Se considerarmos o valor real de $4,88 \mathrm{kWh} / \mathrm{m}^{2} /$ dia a produção deveria ser de $23,2 \mathrm{kWh} /$ dia, representando uma diferença de $34,5 \%$.

\section{Conclusões}

Este artigo apresentou as etapas de desenvolvimento do projeto de geração de energia fotovoltaica composto por dois sistemas distintos; um de geração isolada e outro com conexão com a rede elétrica comercial. Os cálculos e estimativas de energia produzidas para cada inclinação dos painéis foi apresentada bem como a descrição dos principais componentes dos sistemas.

Através da monitorização remota da produção de energia obtém-se diariamente a quantidade gerada além de se poder realizar uma supervisão da operação dos equipamentos que se encontram na planta fotovoltaica.

Os resultados parciais de geração mostram uma produção menor nos primeiros meses de operação, justificados, pelo menos até agora, pelas paradas nos inversores para realização de medições internas, instalação de novos dispositivos e calibrações dos sensores e medidores de energia.

Em fase final de montagem, o grupo de equipamentos do painel 2 já iniciou a operação e os dados de geração de energia e consumo estão 
sendo reunidos. Pretende-se em breve disponibilizar o acesso à homepage do projeto a fim de possibilitar o acompanhamento pelo público interessado no assunto da geração de energia elétrica utilizando a tecnologia fotovoltaica.

A limitação de potência processada pelo Inversor CP também é um caso interessante de pesquisa, a fim de se determinar qual é a melhor relação entre potência do painel e do inversor para alcançar menor custo da energia produzida.

\section{Referências}

CRESESB - Centro de Referência para Energia Solar e Eólica Sérgio Brito / Cepel - Centro de Pesquisas de Energia Elétrica. Potencial Energético Solar - SunData. http://www.cresesb.cepel.br/sundata/index.php. Acessado em 24/02/2011.

DEMONTI, R., MARTINS, D. C. Grid Connected PV System using Two Energy Processing Stages In: $29^{\text {th }}$ Photovoltaic Specialists Conference, Louisiana. Proceedings of the $29^{\text {th }}$ IEEE Photovoltaic Specialists Conference. 2002. v. CD ROM. p.1649 - 1652.

FARRET. F. A, SIMÕES, M. G. Integration of alternative sources of energy. John Wiley \& Sons, Inc. USA. 2006

GREEN, Martin A. Solar Cells - Operating Principles, Technology and System Applications. Englewood Cliffs: Prentice-Hall, 1982. 274 pp.

Jornal do Estado. Fazenda Rio Grande é cidade teste da Copel. Edição de 24 de Setembro de 2010. no 9006. Curitiba.

MACÊDO, W. N. Análise do fator de dimensionamento do inversor aplicado a sistemas fotovoltaicos conectados à rede. Tese de doutorado. Programa Interunidades de Pós-Graduação em Energia da Universidade de São Paulo. Orientador: Prof. Roberto Zilles. São Paulo. 183p. 2004.

MARTINS, F. R., PEREIRA, E. B., ABREU, S. L. de. COLLE, S. Mapas de irradiação solar para o Brasil - Resultados do Projeto SWERA. Anais do XII Simpósio Brasileiro de Sensoriamento Remoto. INPE. Goiânia, Abril 2005. PP. 3137-3145. 